Research Article

\title{
The Mechanism of Interface Dilatancy of Cement Mortar Rockbolts
}

\author{
Yubao Zhan (D), Nan Li, Hui Wang, Pengqiang Zheng, Jun Zhang, and Qihua Liu \\ College of Resources, Shandong University of Science and Technology, Tai'an, Shandong 271019, China \\ Correspondence should be addressed to Yubao Zhan; skd993925@sdust.edu.cn
}

Received 19 May 2020; Revised 12 August 2020; Accepted 31 August 2020; Published 8 September 2020

Academic Editor: Chunshun Zhang

Copyright (C) 2020 Yubao Zhan et al. This is an open access article distributed under the Creative Commons Attribution License, which permits unrestricted use, distribution, and reproduction in any medium, provided the original work is properly cited.

\begin{abstract}
In this paper, the mechanism of the interface dilatancy of cement mortar rockbolts is studied based on the phenomenon of splitting failure of samples with a high sand content in the grouting material in laboratory tests. A conceptual model of the interface layer is used to explain the dilatancy mechanism of the interface. Based on the thick-walled cylinder theory, the causes of splitting failure of the samples are analyzed. By using the numerical simulation method, the influences of different dilatancy angles of the interface layer on the interface shear stress and the radial stress are analyzed. The results show that the sand content of the grouting material has a substantial effect on the bearing capacity of the rockbolt. The higher the sand content in the grouting material is, the more obvious the interface dilatancy will be, and the greater the radial stress generated by dilatancy will be, which will produce a higher bearing capacity of the anchorage system. Under the same load, the maximum shear stress of the interface layer increases with increasing dilatancy angle. Similarly, the larger the dilatancy angle of the interface layer is, the greater the radial stress caused by dilatancy will be. Away from the interface layer, the radial stress decays rapidly. The influence range of the radial stress caused by dilatancy is mainly in the interface layer and the rock nearby.
\end{abstract}

\section{Introduction}

Fully grouted bolts have been widely used in underground engineering applications. Such bolts mainly provide the support force through the shear stress between the bolt and the grout and between the grout and the surrounding rock. According to the different grouting materials, full grouted rockbolts can be divided into two categories: cement mortar grouted rockbolts and resin grouted rockbolts. This research focuses on cement mortar grouted rockbolts.

A large number of studies have shown that interface failure is a common failure mode in anchorage systems $[1-3]$. The interface of the whole anchorage system mainly includes the interface between the grout and the rock and between the grout and the bolt. It is well known that the determination of the anchorage length is one of the most important problems in the design of anchorage structures. The key for determining the anchorage length is to obtain the shear stress at the interface of the anchorage structure. Therefore, it is of great importance to accurately determine the shear stress distribution at the interface for the prediction of the ultimate bearing capacity of the grouted rockbolt [4]. In the current code for the design of anchorage structure (BS 8081:2015), it is still assumed that the interface shear stress is uniformly distributed, although both theory and experiment show that the distribution of the interface shear stress is nonlinear.

Since the application of anchorage structures in engineering practice, many scholars have noticed the importance of the interface stress distribution for the design of anchorage structures. Benmokrane et al. [1] studied the influence of the shape of the bolt surface, water-cement ratio, and different additives on the mechanical properties of the interface. Cao et al. [5] introduced a method of adding a small amount of rigid particles to the grouting material to improve the load transfer capacity of the fully grouted bolt system. Through the uniaxial pull-out test of the fully grouted rockbolts, Teymen and Kilıç [6] found that the grout strength had a considerable effect on the shear stress distribution of the rockbolt. In addition, many field and 
laboratory studies have been carried out on the effects of the bolt surface shape, water-cement ratio, and different additives on the interface mechanical properties [7-9]. These studies played an important role in promoting the understanding of the mechanical properties of the interface. At the same time, scholars have carried out many beneficial studies on the research of the interface shear stress distribution model. In 1995, a trilinear model of shear stress slip was proposed by Benmokrane et al. [1]. Based on the trilinear stress-slip relationship, Ren et al. [10] proposed five stages of the shear stress distribution. Ma et al. [11] proposed a model of the shear stress distribution at the bolt-grout interface, which was consistent with the test results. On the basis of considering the free and slip factors, Ma et al. [12] proposed the closed solution of the shear stress distribution for the bolt-grout interface. Wang et al. [4] proposed a three-dimensional analysis model based on the trilinear bond-slip model for the pull-out response of grouted bolts to describe the bond failure of the bolt-grout interface and derived the closed expressions of the interface shear stress at different pull-out stages. In addition, the distributions of the interface shear stress under different anchorage lengths were analyzed.

It is generally believed that the shear strength of the interface, except for the bond stress, comes from the friction stress at the interface. Yazici and Kaiser [13] believed that the shear strength of a fully grouted bolt is mainly due to friction and its value depends on pressure at the bolt-grout interface. It is also discussed in [14] that the normal stress acting on the rebar is the most important parameter for controlling the bond capacity of the steel bar because of the frictional nature of the bond slip at the interface. The larger the confining stress is, the higher the bearing capacity of the anchorage system is. Therefore, it is worth nothing that the influence of the normal stress on the interface shear stress should not be ignored. In laboratory pull-out tests of bolts, most scholars evaluated the influence of the normal pressure on the bearing capacity by applying a uniform and constant confining pressure to the anchorage system or applying radial constraints around the samples $[15,16]$. It was found that, due to the low radial stiffness of soft rock, radial cracks easily occur. In contrast, hard rock has a high radial stiffness, which will inhibit the generation and development of radial cracks [13]. Thenevin et al. [17] conducted laboratory pullout tests on different types of rockbolts. A similar conclusion was drawn: under the condition of a low confining pressure, radial fractures are found in the grouting material and the rock. The research results of Hyett et al. [7, 8] showed that the miniscule dilatancy caused by bond failure leads to the generation of radial pressure on the cable-grout interface, which improves the friction strength of the interface. With the increase in the radial constraints, the failure mechanism of the grout annulus changes from radial fracturing and lateral displacement under low constraints to shear failure and pull-out along the interface under high constraints. In the above studies, the influence of the surrounding rock stiffness around the borehole on the bearing capacity of the anchorage structure essentially reflects the influence of the interface radial stress on the bearing capacity of the anchorage structure in the loading process. The greater the rock stiffness is, the stronger the radial restraint is (when the interface dilatancy of the anchorage structure occurs), which will lead to the larger radial stress produced by dilatancy. Finally, the shear strength of the interface of the anchorage system is improved. Therefore, it is very important to understand the mechanism of the radial stress on the interface of the anchorage structure, because it has a great impact on the overall performance of the anchorage system. It is generally believed that the radial stress on the interface of anchorage structure mainly comes from two sources: the confining pressure of the anchorage system and the interface dilatancy. The confining pressure is mainly related to the embedded depth and the in situ stress of the anchorage section, while the radial stress generated by the interface dilatancy is related to the interface mechanical properties of the anchorage structure.

After analyzing the literature, it is evident that most scholars focused on the interface between the bolt and the grout. In these studies, the mechanism of dilatancy caused by the roughness of the bolt surface was mainly studied. Surprisingly, scholars paid little attention to the influence of the material composition of the grout, especially the sand content in the cement mortar on the interface dilatancy. Therefore, it is necessary to study the influence of the sand content in the cement mortar on the anchorage mechanism of the anchorage structure. In this paper, the mechanism of the interface dilatancy of cement mortar rockbolts is studied by laboratory tests. The reason for the splitting failure of samples and the mechanism of interface dilatancy are analyzed. Based on the numerical simulation, the influence of different dilatancy degrees of the interface layer on the interface shear stress and the radial stress is analyzed. The research results can provide a reference for the design of cement mortar rockbolts, which can optimize the design and promote the development of anchorage theory.

\section{Experimental Study}

2.1. Experimental Scheme. The purpose of this experiment is to analyze the influence of the sand content in the cement mortar on the anchorage mechanism of the anchorage structure. The influence of the rockbolt length and sand content in the cement mortar on the anchorage mechanism is considered.

2.1.1. Sample Preparation. A new set of molds is developed to make the samples, as shown in Figure 1. Two thin-walled cylinders are assembled together with two sets of jointed bolts to form a cylinder. The diameter of the cylinder is $159 \mathrm{~mm}$ and the thickness of the cylinder wall is $6 \mathrm{~mm}$. A galvanized steel tube with a diameter of $42.3 \mathrm{~mm}$ is placed in the center of the cylinder, which is used to reserve the drilling hole when pouring concrete. Three M16 rods are embedded in the concrete sample, which are connected to the steel plate at the bottom. A pull rod is welded at the center of the steel plate, and the pull rod is on the same axis as the rockbolt anchored in the sample. 


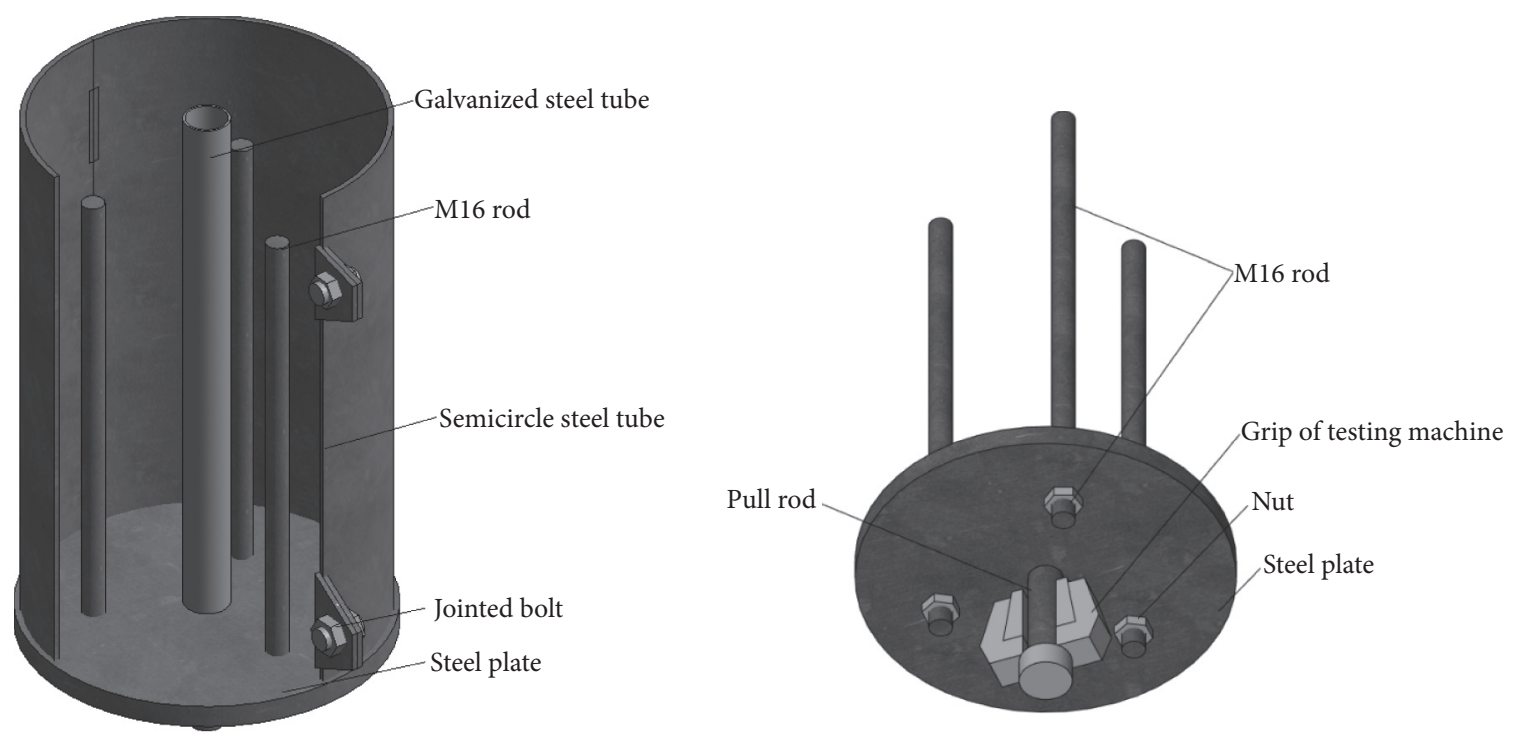

Figure 1: Diagram of the mold.

C40 concrete is poured to simulate rock, and the heights of the samples are $150 \mathrm{~mm}, 200 \mathrm{~mm}, 250 \mathrm{~mm}$, and $300 \mathrm{~mm}$. Cement mortar is used as the grouting material, and the cement-sand ratios (volume ratio) of the grouting material are $1: 0,1: 1$, and $3: 1$. The cement is ordinary Portland cement, and the sand is quartz sand. Table 1 lists the sample ID corresponding to the cement-sand ratio and anchorage length.

2.1.2. Rockbolt Installation. The rockbolt is simulated with a $16 \mathrm{~mm}$ diameter HRB335 steel bar. The steel bar is inserted into the center of the bore hole, and the cement mortar is injected into the hole. To make the cement-sand denser, the pouring process is carried out on a shaking table. The sample after pouring is shown in Figure 2.

2.1.3. Loading Scheme. After the samples are cured and meet the test requirements, the bottom of the sample is connected to the steel plate. The pull rod at the bottom of the steel plate is placed in the lower grip of the testing machine. The upper grip of the testing machine is connected to the rockbolt anchored in the sample. It should be noted that the lower pull rod and the upper rockbolt must be on the same axis, as shown in Figure 3. Displacement loading is adopted in this test until the anchorage system fails. The load-displacement data of each sample are recorded by a computer.

2.2. Material Properties of the Cement Mortar. According to the standards for test method of performance on building mortar (JGJ/T70-2009) [18], the mechanical properties of cement mortar are determined by laboratory tests. The mechanical properties of the cement mortar are shown in Table 2.

\subsection{Results and Analysis}

2.3.1. Failure Modes. The failure modes of all the samples in the test are shown in Table 3. There are only two failure modes of the samples: debonding failure at the grout- concrete interface and splitting failure of the concrete. Debonding failure occurs when the rockbolt and the grout are pulled out of the concrete as a whole, and the interface between the grout and the concrete experiences debonding (as shown in Figure 4). Splitting failure occurs when concrete cracks (as shown in Figure 5) in the process of rockbolt bearing pull-out loading, and the anchorage system loses its bearing capacity.

2.3.2. Mechanism of Dilatancy. In this test, although there is no restraint around the sample, the failure load of the sample is not consistent with the real bearing capacity of the anchorage system. However, it is precisely because of this that there is an opportunity to find a very regular phenomenon in the test; that is, most samples with splitting failure are those with more sand content in the cement mortar, and the failure loads of the samples with a high sand content are much larger than those of the other samples. Table 4 shows the failure loads of samples with $1: 0,1: 1$, and $1: 3$ cementsand ratios for the same anchorage length. The failure load of the sample has little correlation with the modulus of elasticity, uniaxial compressive strength, and other factors of the cement mortar, but it shows a strong correlation with the sand content of the cement mortar. With the increase in the sand content, the bearing capacity of the sample increases substantially, and the increase range is great. This promotes interest in the influence of the sand content of the grouting material on the bearing capacity of the anchorage system. Due to the splitting failure of some samples, such as 1-3, 2-3, and 3-3, their failure loads in the test cannot fully reflect the real impact of the sand content ratio. For samples 4-0 and 43 with the same failure mode, their failure loads should have more referential value. The cement-sand ratio of the cement mortar increases from $1: 0$ to $1: 3$, and the corresponding failure load increases from $4.7 \mathrm{kN}$ to $21.9 \mathrm{kN}$, which is an increase of nearly five times. Obviously, the sand content of the grouting material has a substantial effect on the bearing capacity of the anchorage system. 
TABLE 1: Sample ID, cement-sand ratio, and anchorage length.

\begin{tabular}{|c|c|c|c|c|c|c|c|c|c|c|c|c|}
\hline Sample ID & $1-0$ & $2-0$ & $3-0$ & $4-0$ & $1-1$ & $2-1$ & $3-1$ & 4-1 & $1-3$ & $2-3$ & $3-3$ & 4-3 \\
\hline $\mathrm{Ce}$ & $1: 0$ & $1: 0$ & $1: 0$ & $1: 0$ & $1: 1$ & $1: 1$ & $1: 1$ & $1: 1$ & $1: 3$ & $1: 3$ & $1: 3$ & $1: 3$ \\
\hline Anchorage length (mm) & 300 & 250 & 200 & 150 & 300 & 250 & 200 & 150 & 300 & 250 & 200 & 150 \\
\hline
\end{tabular}

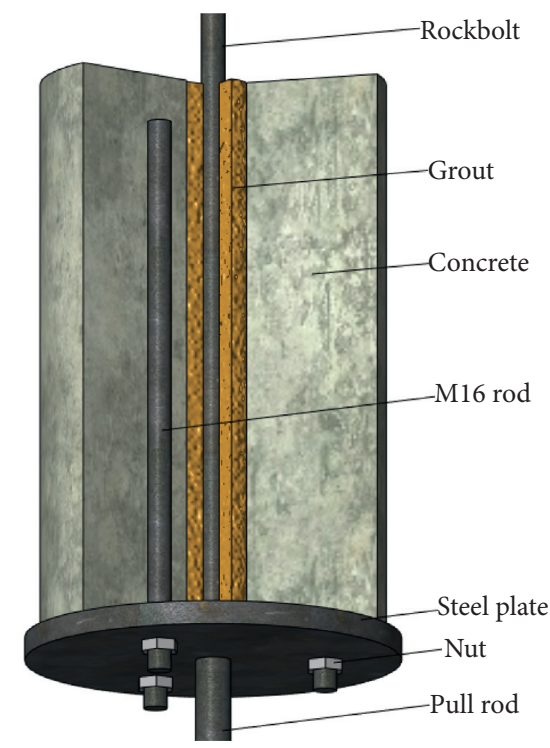

FIGURE 2: Sample after pouring.

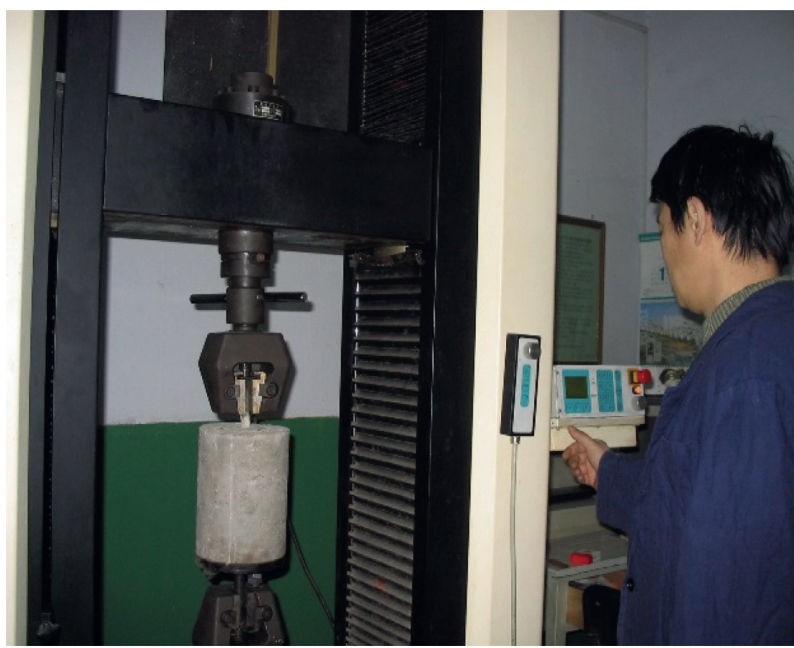

Figure 3: Sample mounted on the testing machine.

TABLE 2: Material properties of the cement mortar.

\begin{tabular}{lcc}
\hline Cement-sand ratio & $\begin{array}{c}\text { Cubic compressive } \\
\text { strength }(\mathrm{MPa})\end{array}$ & $\begin{array}{c}\text { Elastic modulus } \\
(\mathrm{GPa})\end{array}$ \\
\hline $1: 0$ & 24.2 & 20.5 \\
$1: 1$ & 21.4 & 18.9 \\
$1: 3$ & 10.3 & 16.1 \\
\hline
\end{tabular}

The dilatancy at the interface of the anchorage structure is generally believed to be caused by relative slip between the steel bar with a rough surface and the grouting material [14].
In this test, debonding failure occurs between the grout and the concrete. Furthermore, the borehole of the sample is reserved by the galvanized steel tube, and the surface of the borehole is relatively smooth, so the cause of dilatancy is not related to the roughness of the borehole. Based on the above analysis, the dilatancy found in this test must be related to the sand content in the grouting material.

Under the same conditions, it is unexpected that the sand content in the grouting material has a substantial effect on the bearing capacity of the anchorage system. This shows that the radial stress produced by dilatancy is very large in 
TABLE 3: Failure modes of the samples.

\begin{tabular}{llr}
\hline Failure mode & Debonding failure & Splitting failure \\
\hline \multirow{2}{*}{ Sample ID } & $1-0,2-0,3-0,4-0$, & $1-1,1-3,2-3,3-3$ \\
\hline
\end{tabular}

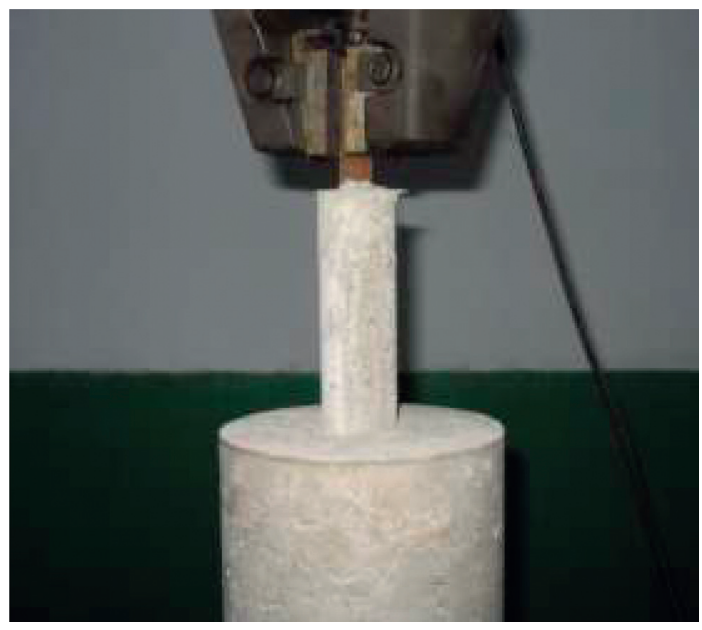

Figure 4: Debonding failure of the sample.

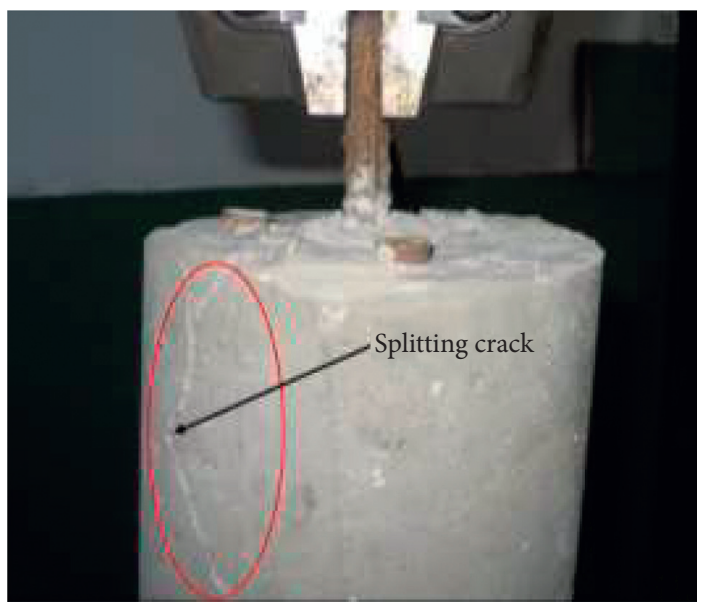

FIGURE 5: Splitting failure of the sample.

TABLE 4: Failure loads of the samples $(\mathrm{kN})$.

\begin{tabular}{lcccc}
\hline \multirow{2}{*}{ Cement-sand ratio } & \multicolumn{3}{c}{ Anchorage length (mm) } \\
& 300 & 250 & 200 & 150 \\
\hline $1: 0$ & 14.0 & 3.5 & 8.1 & 4.7 \\
$1: 1$ & 20.4 & 16.7 & 9.8 & 12.0 \\
$1: 3$ & 48.9 & 59.1 & 41.9 & 21.9 \\
\hline
\end{tabular}

Failure loads of the samples with splitting failure are in italics in the table.

the sample with a high sand content. This problem can also be explained by the surface status between the grout and the concrete after the splitting failure of the sample. Figure 6 shows the surface statuses of the grouting body of samples 2 0 and 2-3. According to the surface abrasion of the grouting body, the abrasion degree of sample 2-3 is much larger than that of sample 2-0, which indicates that the interface of sample 2-3 between the grouting body and the concrete is subjected to more shear stress than that of sample 2-0 in the process of interface slip.

Figure 7 shows the surface statuses of the borehole of the splitting failure sample (Sample 2-3). Figures 6 and 7 show 


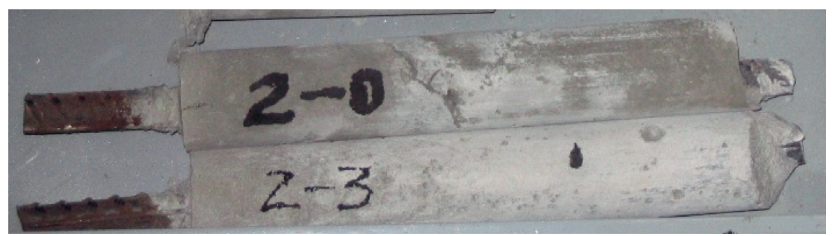

Figure 6: Surface statuses of the grouting body.

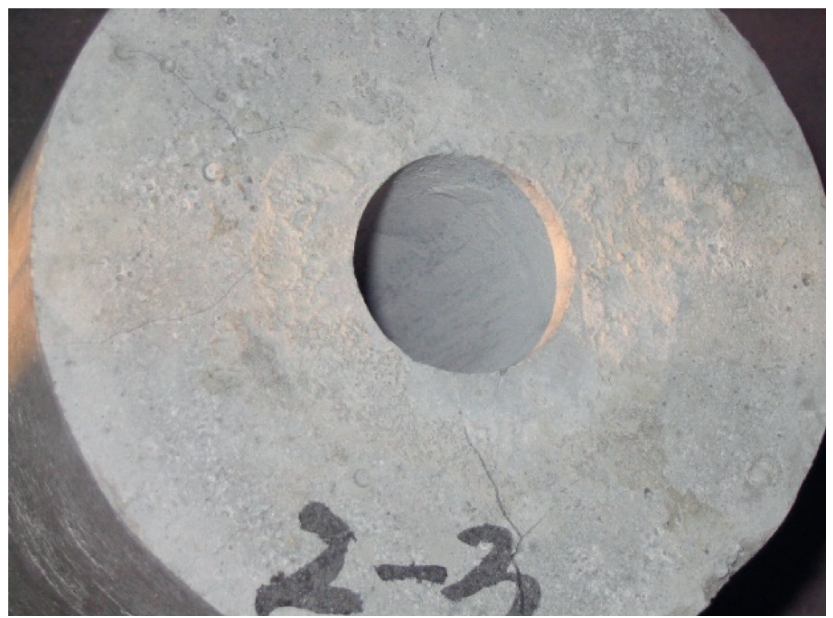

FIGURE 7: Surface statuses of the borehole of the splitting failure sample.

that the surface of the borehole is relatively smooth, while the surface of the grouting body is seriously worn, which indicates that the interface layer of dilatancy is on the side close to the grouting body. Therefore, the mechanical properties of the interface between the grouting body and the rock are mainly controlled by a layer of sand "shear zone" close to the grouting body. Figure 8 is a conceptual model of the interface layer. It is assumed that the arrangement of the sand particles on the surface of the grouting body before interface slip is as shown in Figure 8(a) and the thickness of the interface layer is $L_{0}$. With increasing load, the relative sliding distance of the interface increases. At a certain time, the relative positions of particle $J$ and particle $\mathrm{K}$ are shown in Figure 8(b). At this time, the length of the interface layer is $L$. Compared with Figure $8(a)$, the thickness of the interface layer increases by $\triangle L$, resulting in obvious dilatancy of the interface. If the relative slip between the grouting body and the concrete continues to increase, when the relative position between the sand particles is as shown in Figure 8(c), the thickness of the interface layer changes to $L_{1}$, and the interface dilatancy obviously decreases. If the slip continues to increase, the interface dilatancy disappears.

2.3.3. Load-Displacement Response. The load-displacement curves of samples 2-0 and 2-3 are shown in Figure 9. Debonding failure occurred in sample 2-0, while splitting failure occurred in sample 2-3. Except for the different sand contents of the grouting materials, the other conditions were the same. The load-displacement curves showed that the failure load of the samples with a high sand content ratio was much larger than that of samples with a low sand content ratio. When the pull-out load reached a peak, the concrete split and instantaneous "collapse" occurred, and the whole anchorage system lost its bearing capacity. Obviously, the peak load of sample 2-3 was not the real ultimate bearing capacity of the whole anchorage system due to splitting failure, and the potential of its bearing capacity had not been fully developed. It can be predicted that the bearing capacity of the anchorage system will be higher if the radial restraint or confining pressure of the samples is considered.

Figure 10 shows the load-displacement curves of the samples with a cement-sand ratio of $1: 3$. Among the four samples with the highest sand content, only sample 4-3 failed to split. The load-displacement curve of sample 4-3 experienced four typical stages, while the other samples only experienced the first two stages.

Linear stage (OA): in this stage, the deformation of the anchorage structure is very small, and the interface has not yet produced relative slip. The deformation mainly comes from the elastic deformation of the steel rockbolt. Therefore, the load-displacement curve in this stage is approximated as a straight line. As shown in Figure 10, the deformation characteristics of the curves of all the samples are relatively consistent in this stage. Their deformations are very small, and they are less than $1 \mathrm{~mm}$ under this test condition.

Dilatancy-hardening stage (AP): in this stage, the interface begins to experience relative slip, and interface dilatancy appears. With the increase in the pull-out load, the interface near the load end begins to debond, and the interface dilatancy effect is more obvious. In this stage, the 


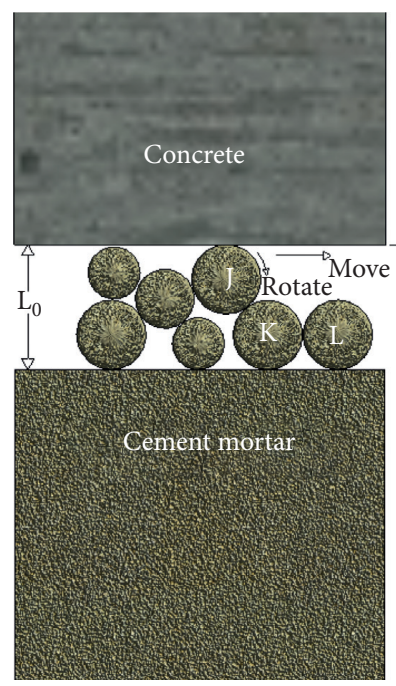

(a)

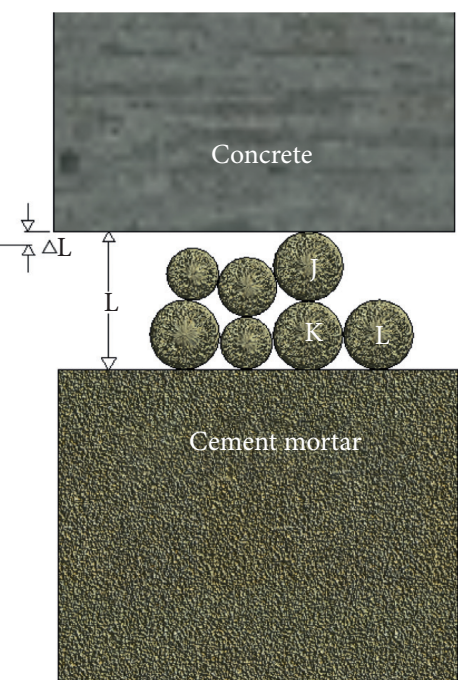

(b)

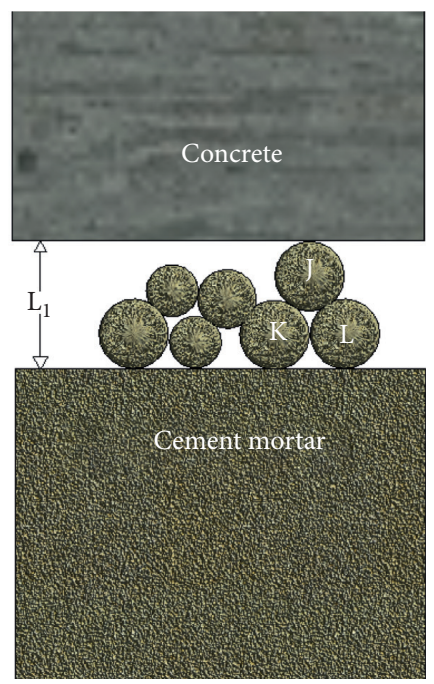

(c)

FIGURE 8: Conceptual model of the interface layer.

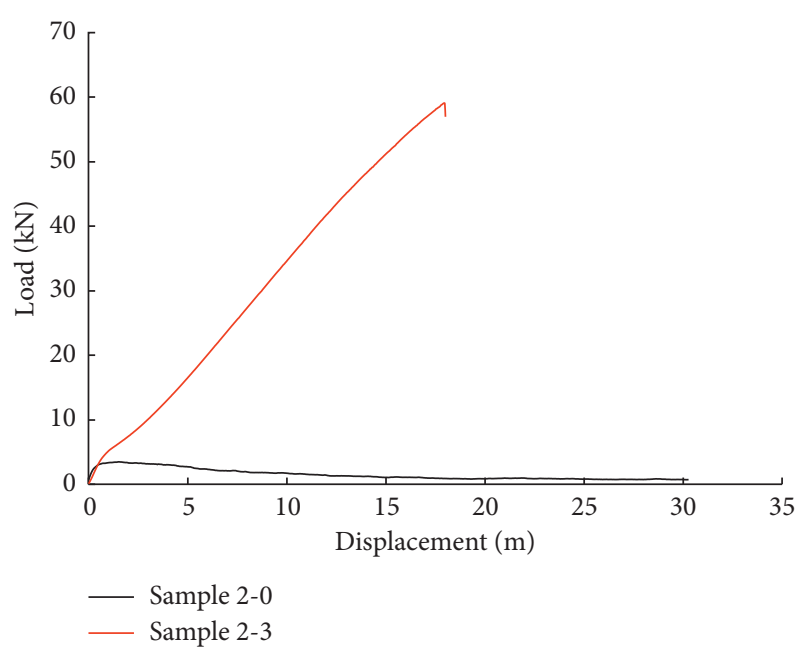

FIgURE 9: Load-displacement curves of samples 2-0 and 2-3.

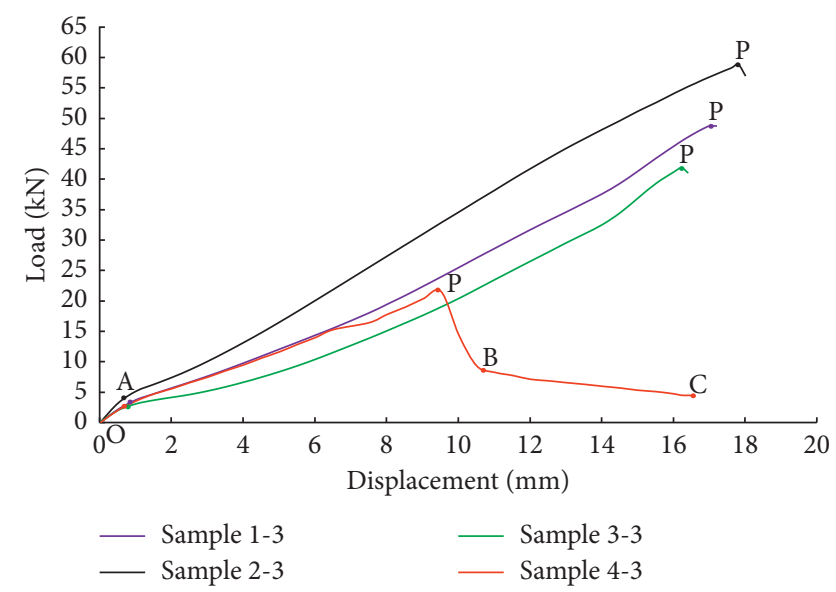

FIGURE 10: Load-displacement curves of samples with a cementsand ratio of $1: 3$. pull-out load of the anchorage structure does not decrease but increases with increasing displacement. The dilatancy has a substantial effect on the bearing capacity. With the increase in the load, the interface debonding moves from the load end to the depth, the relative length of the interface slip increases gradually, the dilatancy effect becomes increasingly substantial, and the radial stress generated by dilatancy becomes increasingly larger. As a result, radial splitting failure of the concrete occurs, and the whole anchorage structure suddenly collapses and fails. Because the anchorage length of sample $4-3$ is only $150 \mathrm{~mm}$, the interface slip distance is short, the radial stress generated by dilatancy is relatively small, and the concrete has not split.

Dilatancy-softening stage (PC): as seen from the loaddisplacement curve of sample 4-3 in Figure 10, after the peak point $\mathrm{P}$, the interface dilatancy gradually decreases, and the load also gradually decreases with the increase in the displacement, showing obvious softening characteristics. However, it should be noted that although the bearing capacity of the anchorage system obviously decreases after reaching the peak, it does not completely lose its bearing capacity. This is quite different from the sudden collapse failure of the sample with splitting failure.

Residual stress stage (CD): in this stage, with increasing relative sliding distance of the interface, the interface dilatancy disappears completely. Only the residual shear stress on the interface is left. With increasing displacement, the contact area of the interface decreases, and the bearing capacity of the anchorage system gradually decreases until the rockbolt and grout are pulled out.

By comparing Figures 9 and 10, it is evident that there is no obvious difference in the load-displacement curves of all the samples at the initial stage (OA). With increasing load, the load-displacement curves of the samples with different sand contents in the grouting material are obviously different. Under the same conditions, the bearing capacity of the sample with a high sand content is obviously higher than 
that of the other samples. Combined with the laboratory tests, it is evident that the higher the sand content in the grouting material is, the greater the interface roughness between the grouting body and rock is. The rougher the interface is, the more obvious the dilatancy is. Because of the large radial stress produced by the dilatancy, the shear strength of the interface is directly increased. When the radial stress on the interface is large, the specimen will crack. Therefore, the load-displacement curves of the samples with splitting failure have only the first two stages (OA and AP). In conclusion, with the increase in the sand content in grouting materials, the bearing capacity of the anchorage structure also increases.

2.3.4. Reason for Splitting Failure. The rock material concrete strength refers to the maximum load that it can bear when it is damaged under an external load. The determination of the mechanical strength of rock materials is still confined to the traditional solid mechanics system that takes homogeneous materials such as metals as research objects. Although some new research methods have been reported recently $[19,20]$, some mechanical concepts of traditional solid mechanics are still used, such as the yield criterion of traditional solid mechanics. Among them, the maximum tensile stress criterion is the first theory on the strength of materials under complex stress conditions. According to the theory, the main factor that causes material fracture is the maximum tensile stress. The test results show that the maximum tensile stress criterion of brittle materials is close to the test results when they experience biaxial or triaxial tensile fracture. When there is compressive stress, as long as the maximum compressive stress does not exceed the maximum tensile stress, the maximum tensile stress criterion is approximately similar to the test results.

When splitting failure occurs, the inner wall of the borehole must be subjected to radial stress. During the test, there is no restraint or confining pressure around the sample, so the source of the radial stress is caused by the interface dilatancy when the interface between the grouting body and the concrete produces relative slip. Figure 11 shows a schematic diagram of the stress on the borehole and the surrounding concrete. According to elastic theory [21], the tangential stress $\sigma_{\theta}$ and the radial stress $\sigma_{r}$ at any point $r$ away from the center of the borehole are

$$
\begin{gathered}
\sigma_{\theta}=\frac{P_{2} R_{2}^{2}-P_{1} R_{1}^{2}}{R_{2}^{2}-R_{1}^{2}}+\frac{\left(P_{2}-P_{1}\right) R_{2}^{2} R_{1}^{2}}{r^{2}\left(R_{2}^{2}-R_{1}^{2}\right)}, \\
\sigma_{r}=\frac{P_{2} R_{2}^{2}-P_{1} R_{1}^{2}}{R_{2}^{2}-R_{1}^{2}}-\frac{\left(P_{2}-P_{1}\right) R_{2}^{2} R_{1}^{2}}{r^{2}\left(R_{2}^{2}-R_{1}^{2}\right)},
\end{gathered}
$$

where $r$ is the radial distance, $\mathrm{m} ; P_{1}$ and $P_{2}$ are the inner and external wall pressures acting on the thick-walled cylinder, respectively, MPa; and $R_{1}$ and $R_{2}$ are the inner and outer diameters of the thick-walled cylinder, respectively, $\mathrm{m}$. The distribution curves of $\sigma_{\theta}$ and $\sigma_{r}$ for concrete are shown in Figure 11. Under the condition of this test, only radial stress produced by dilatancy is exerted in the borehole. According

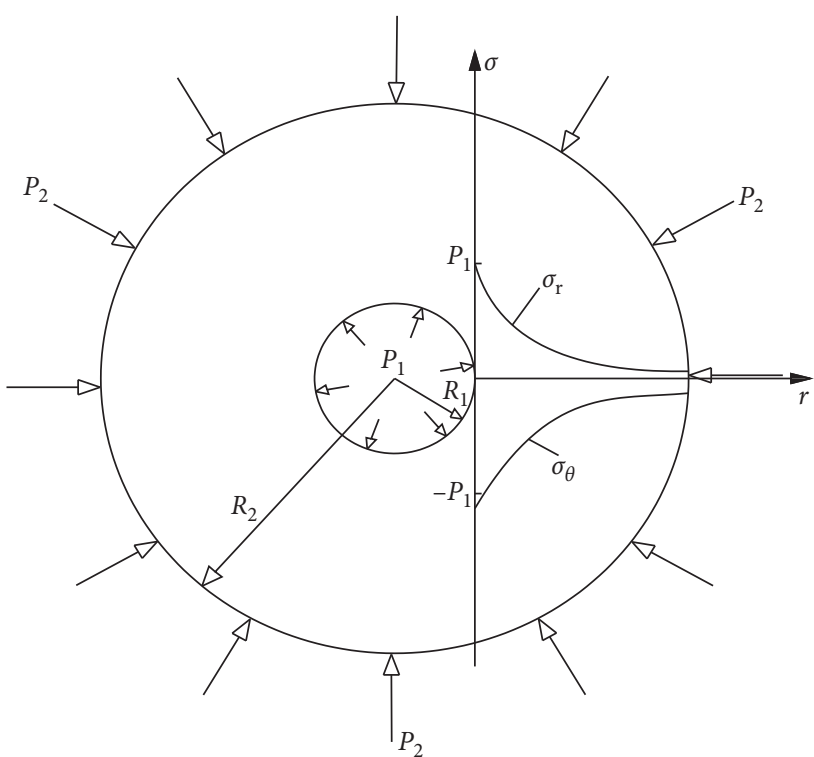

FIgURE 11: Schematic diagram of the stress on the borehole and the surrounding concrete.

to (1), when $P_{1} \neq 0$ and $P_{2}=0$, the tangential stress is $\sigma_{\theta}=$ $-P_{1}\left(R_{2}^{2}+R_{1}^{2} / R_{2}^{2}-R_{1}^{2}\right)$ on the borehole wall $\left(r=R_{1}\right)$. Because $\sigma_{\theta}<0$, the radial stress $\sigma_{\theta}$ is tensile stress. When the radial stress generated by dilatancy reaches a certain value, then $P_{1}\left(R_{2}^{2}+R_{1}^{2} / R_{2}^{2}-R_{1}^{2}\right)>\sigma_{t}\left(\sigma_{t}\right.$ is the tensile strength of concrete). The radial tensile stress on the borehole wall exceeds the tensile strength of the concrete, and the sample will be split. In this test, $\sigma_{t}=1.71 \mathrm{MPa}, R_{1}=21.15 \mathrm{~mm}$, and $R_{2}=76.5 \mathrm{~mm}$, and substituting these parameters into (1) gives $P_{1}=1.47 \mathrm{MPa}$. In other words, when the concrete is cracked, the pressure acting on the borehole wall is $1.47 \mathrm{MPa}$.

2.3.5. Influence of the Dilatancy on the Shear Strength. After there is dilatancy of the interface, the shear strength of the interface is generally expressed by the following equation:

$$
\tau_{p}=\left(\sigma_{n}+\Delta \sigma_{n}\right) \tan \varphi+C,
$$

where $C$ is the cohesion of the interface, MPa; $\varphi$ is the internal friction angle of the interface, degree; $\sigma_{n}$ is the normal stress on the anchorage section before dilatancy, $\mathrm{MPa}$; and $\Delta \sigma_{n}$ is the change in the normal stress due to dilatancy, MPa. $\Delta \sigma_{n} \tan \varphi$ is the increase part of the interface shear strength due to the radial stress caused by dilatancy.

According to the elastic theoretical solution for a thickwalled cylinder, the increment of the normal stress when the cylinder wall expands radially is as follows [22]:

$$
\Delta \sigma_{n}=\frac{E_{r}}{1+v_{r}} \frac{\Delta L}{D},
$$

where $E_{r}$ is the elastic modulus of the rock, MPa; $v_{r}$ is Poisson's ratio of the rock; $D$ is the diameter of the borehole, $\mathrm{m}$; and $\Delta L$ is the radial expansion of the borehole wall, $\mathrm{m}$. 
Since the normal stiffness $K=\left(E_{r} / 1+v_{r}\right) 1 / D$, the normal stress increment is linear with radial expansion. Assuming $D=60 \mathrm{~mm}, E_{r}=32.5 \mathrm{GPa}$, and $v_{r}=0.21$, the radial stiffness of the rock around the borehole can be obtained as $K=2.24 \times 10^{11} \mathrm{~Pa} / \mathrm{m}$. When the radial deformation of rock is $4.47 \times 10^{-3} \mathrm{~mm}$, the change in the radial stress caused by the radial deformation is $1 \mathrm{MPa}$. It is evident that the radial deformation caused by dilatancy has a substantial effect on the radial stress. Moreover, according to (3), it is obvious that the increase in the radial stress $\Delta \sigma_{n}$ is of great importance for the improvement of the interface shear strength.

\section{Numerical Simulation}

The physical model test can obtain accurate and reliable results when carried out under strictly controlled test conditions. However, it takes considerable time and money to study the parameters through physical model testing. Moreover, some parameters are difficult to change in physical model tests, such as the dilatancy angle. Numerical simulations can effectively solve this problem. It is very convenient to study the parameters by changing only one parameter at a time. At present, it is true that the selection of input data and parameters does not fully match the actual situation in the numerical simulation. However, we can focus on the influence of the parameters on the dilatancy from the overall trend rather than the accurate value and detailed analysis.

3.1. Numerical Model. Although the three-dimensional problem is closer to the actual situation, to save calculation time and improve analysis convenience, the calculation model is simplified as an axisymmetric problem. The dead weight of the rockbolt, the grouting body, and the rock is not included in the analysis. The bottom boundary of the model is constrained by the vertical displacement, while the vertical boundary is constrained by the horizontal direction. The numerical calculation model is shown in Figure 12. In the model, the rockbolt diameter is $32 \mathrm{~mm}$, the borehole diameter is $60 \mathrm{~mm}$, the anchorage length is $2000 \mathrm{~mm}$, and the distance between the rock boundary and the borehole center is $500 \mathrm{~mm}$. The rockbolt, grouting material, and rock are simulated by using PLANE42 in the ANSYS library. Compared with the LINK element, the rockbolt simulated by PLANE42 can bear not only the axial force but also the radial force.

It can be seen from the results of the laboratory model test that the main position of dilatancy is the contact surface between the grouting body and the concrete. At present, although there are many interface models that are commonly used in numerical calculations to simulate the contact between the rock and the grouting body, none of these models can simulate the dilatancy characteristics of the interface. Therefore, in this numerical calculation, an interface layer is set between the grouting body and the rock. This interface layer is not a surface but a solid with a certain thickness, which can simulate the dilatancy behavior of the interface. The thickness of the interface layer between the grouting body and the rock may depend on many factors, such as the method of forming the interface and the physical and mechanical properties of the grouting material. Unfortunately, the thickness of this interface layer is still unknown in the existing literature. In this study, considering the following factors, the thickness of the interface layer is selected as $2 \mathrm{~mm}$ :

(1) The sand commonly used in practical engineering applications can be divided into fine, medium, and coarse types according to the particle size. The average particle sizes are $0.125-0.25 \mathrm{~mm}, 0.25-0.5 \mathrm{~mm}$, and $0.5-1 \mathrm{~mm}$. According to the surface wear of the grouting body after the test, as shown in Figure 6, and the movement of the sand particles, as shown in Figure 8, it is appropriate to set the thickness of the interface layer to 2 times the particle diameter, i.e., $0.5-2 \mathrm{~mm}$. At the same time, considering that the interface layer is too thin, it is difficult to reflect the dilatancy of the interface layer in the numerical simulation.

(2) In [23-25], the thickness of the interface layer between the soil and the structural layer is determined to be $2-8 \mathrm{~mm}$. Considering that the soil layer is relatively soft, the selection of the interface layer thickness will be larger. In this study, the interface layer appears on one side of the grouting body, which is much harder than the soil. It is reasonable to take a small value for the thickness.

(3) A numerical analysis model with the same size and boundary conditions as in the laboratory test is established, and the thickness of the interface layer is verified. The calculation results of the numerical simulation are in agreement with the results of the laboratory test, as shown in Figure 13.

The size of the mesh element is selected appropriately to obtain better convergence, so that substantial computing time is not needed. The finite element mesh is shown in Figure 12(b).

3.2. Material Modeling. The rockbolt is simulated by an isotropic material and the cement mortar; rock and interface layer are simulated by the Drucker-Prager material model, which can reflect the dilatancy of the material. The material parameters are shown in Table 5. A numerical model with the same dimensions, boundary conditions, and load applied to the laboratory model is established, and the mechanical parameters are verified. The failure loads of samples 1-0, 1-1, and 1-3 obtained by the numerical simulation are close to those obtained by laboratory tests, as shown in Figure 13, which shows that the parameters selected in this numerical calculation are reliable.

One is to regard the yield function of the material as the plastic potential function of the material, namely, the associated flow rule. In this case, the internal friction angle is equal to the dilatancy angle. The disadvantage of this method is that the influence of the dilatancy angle is given too much consideration.

The other method is the nonassociated flow rule, when the dilatancy angle is equal to zero, and the influence of the dilatancy angle is not considered at all. 


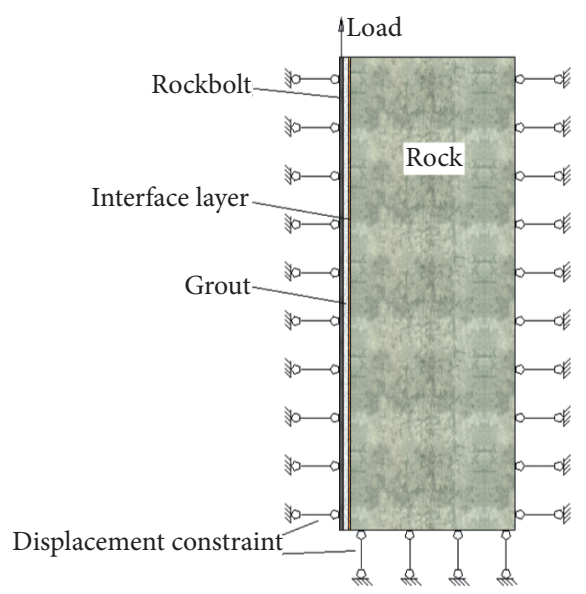

(a)

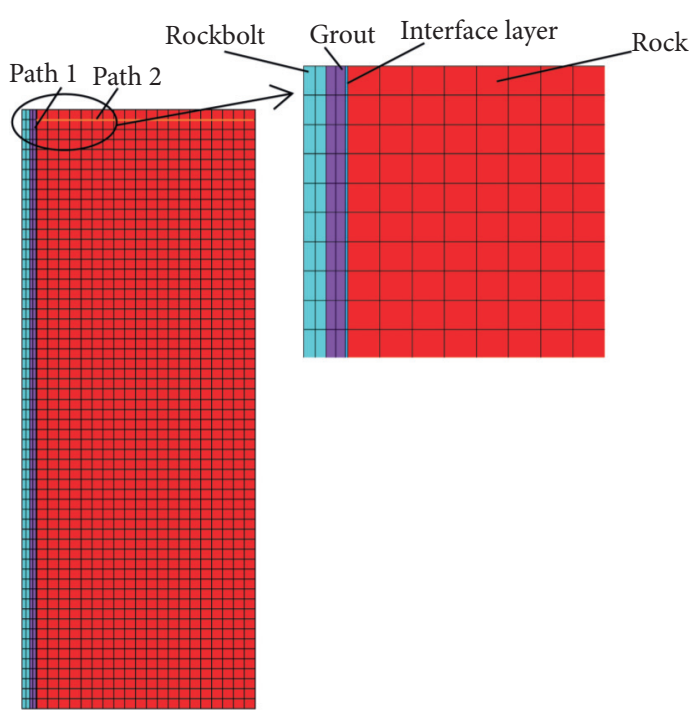

(b)

FIgURE 12: (a) Overview of the model; (b) mesh for the numerical model.

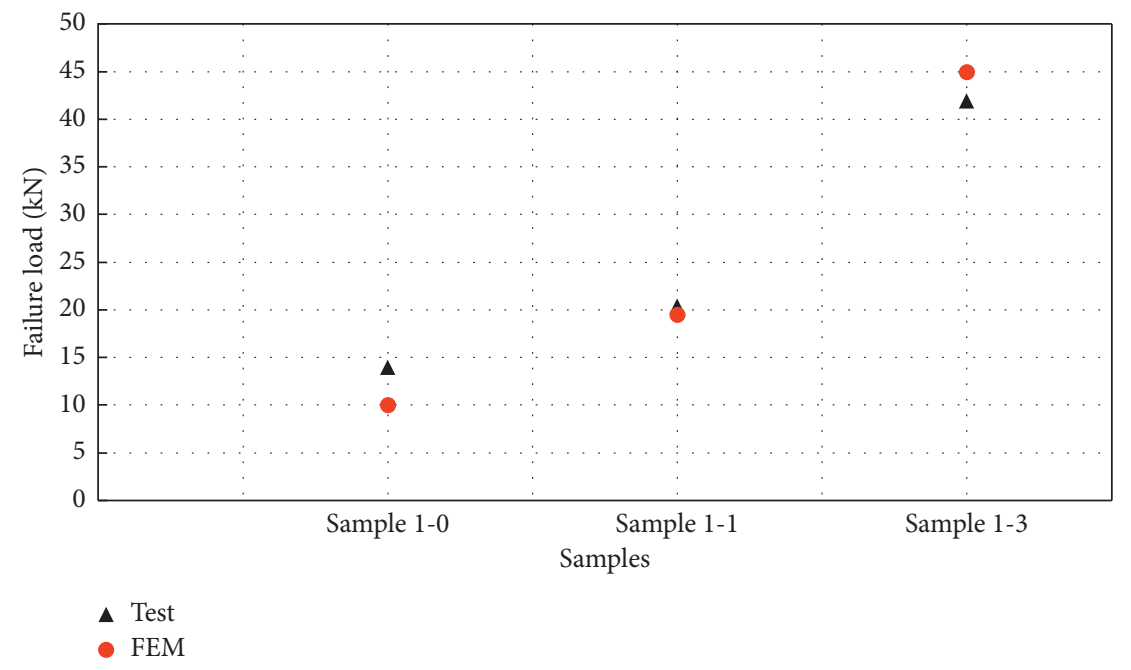

FIgURE 13: Comparison between the numerical simulation and laboratory test results.

In this numerical simulation, the dilatancy angle of the interface layer is set to $5^{\circ}, 10^{\circ}, 15^{\circ}, 20^{\circ}, 25^{\circ}$, and $30^{\circ}$, respectively, to characterize the dilatancy effect of the interface layer, and the influence of the interface dilatancy on the interface shear stress and the bearing capacity of the anchorage structure is studied.

3.3. Influence of Dilatancy on the Interface Shear Stress. A pull-out load of $200 \mathrm{kN}$ is applied to the rockbolt, and path 1 is defined on the outside of the interface layer, as shown in Figure 12(b). The shear stresses obtained by the numerical calculation are mapped to path 1 to obtain the distributions of the interface shear stress under different dilatancy angles, as shown in Figure 14. Figure 15 shows the maximum shear stress of the interface under different dilatancy angles. Figures 14 and 15 show that the maximum value of the interface shear stress increases with increasing dilatancy angle. When the dilatancy angle is small, the slope of the curve in Figure 15 is large, and the maximum shear stress of the interface layer is sensitive to the dilatancy angle. When the dilatancy angle increases to a certain value, the slope of the curve tends to zero, and the change in the dilatancy angle has little effect on the maximum shear stress. The above trend shows that the influence curve of the dilatancy angle on the maximum shear stress of the interface is convergent.

When the dilatancy angle is $\psi=0$, the anchorage system fails when the load reaches $20 \mathrm{kN}$ in the numerical calculation. This indicates that the shear failure of the interface occurs quickly in the loading process because the dilatancy is 
TABLE 5: Mechanical parameters of the materials.

\begin{tabular}{lcccc}
\hline & $E(\mathrm{GPa})$ & $\mu$ & $c(\mathrm{MPa})$ & \\
\hline Rockbolt & 200 & 0.3 & & \\
Grout & 18 & 0.24 & 1 & 35 \\
Rock & 32.5 & 0.21 & 3.8 & 56 \\
Interface layer & 2 & 0.35 & 0.5 & 30 \\
\hline
\end{tabular}

At present, there are two extreme methods for addressing the dilatancy angle.

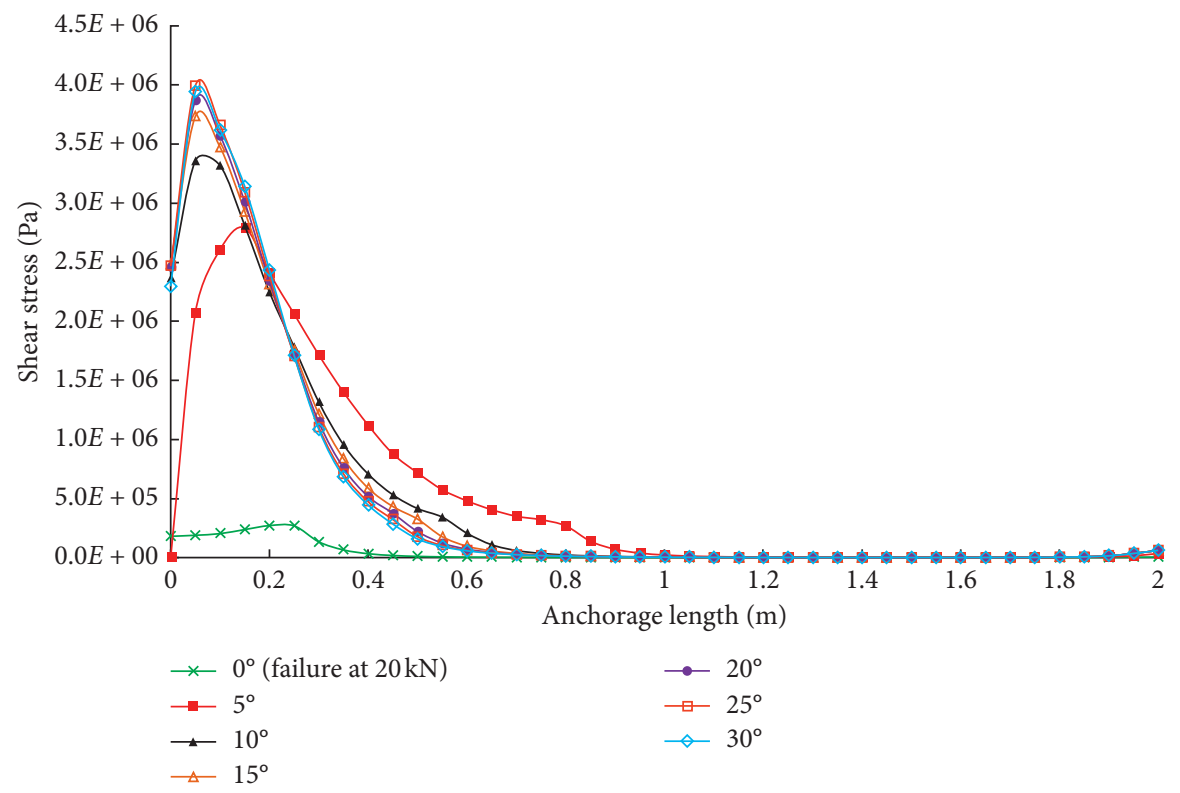

FIgURE 14: Distributions of the interface shear stress under different dilatancy angles for a rockbolt load of $200 \mathrm{kN}$.

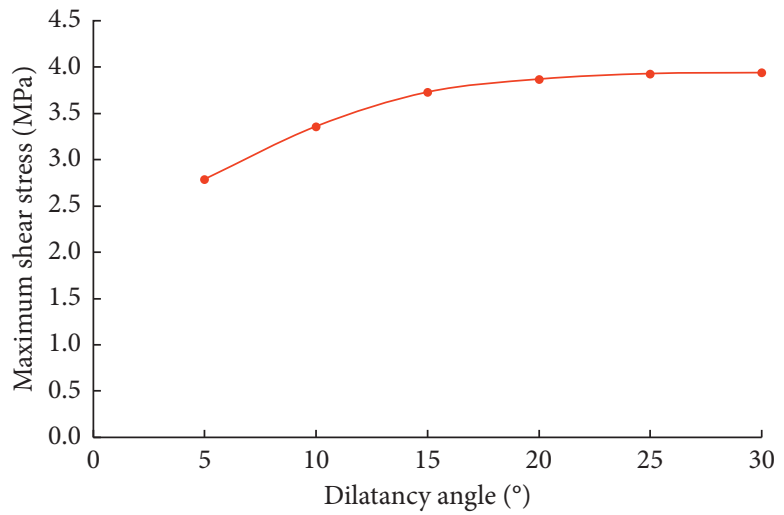

FIgURE 15: Maximum shear stress at the interface under different dilatancy angles.

not considered. Of course, this is an extreme case, which generally does not exist in reality. However, the appearance of this phenomenon also fully shows that the dilatancy has a substantial impact on the bearing capacity of the anchorage system.

3.4. Influence of the Dilatancy on the Radial Stress. The radial stresses around the borehole obtained by the numerical calculation are mapped to path 2 to obtain the curves of the radial stress under different dilatancy angles, as shown in Figure 16. Figure 17 shows the maximum radial stress at the interface under different dilatancy angles.

As seen from Figure 17, when $\psi=0$, the radial stress around the borehole is very small, so it can be considered that there is no radial stress around the borehole wall. The calculation result also explains why the interface layer is damaged when the anchorage structure is subjected to a $20 \mathrm{kN}$ 


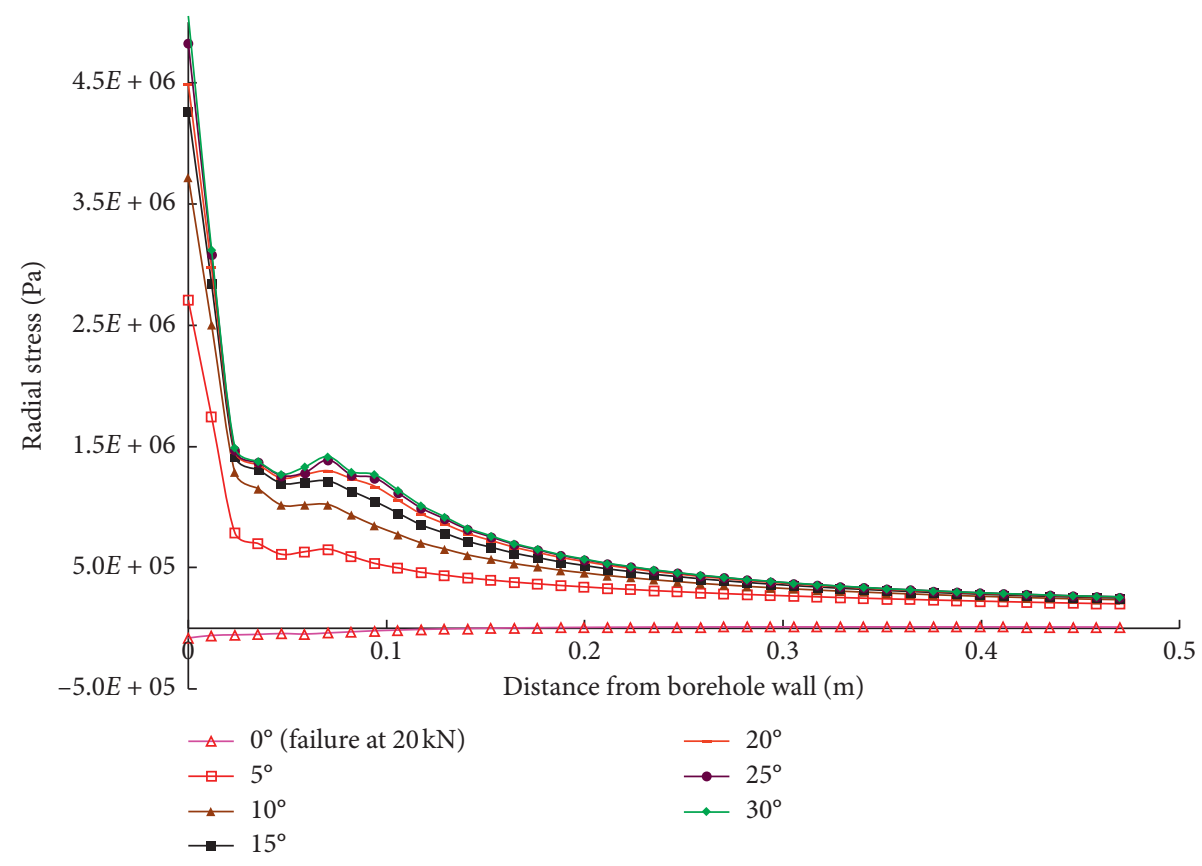

FIGURE 16: Curves of the radial stress under different dilatancy angles.

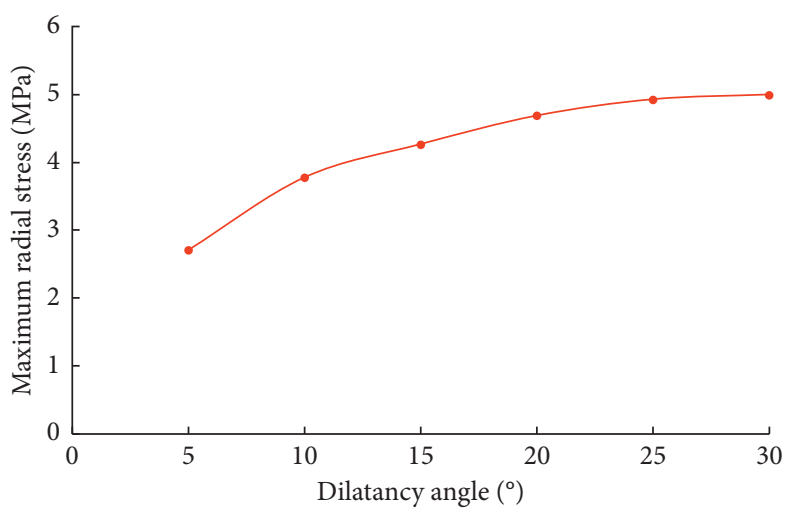

Figure 17: Maximum radial stress at the interface under different dilatancy angles.

pull-out load. According to the Mohr-Coulomb strength in (5), the shear strength of the interface is only the cohesion $C_{s}$, that is, $\tau_{s}=C_{s}$. Because the cohesion of the interface layer in the numerical model is $C_{s}=0.35 \mathrm{MPa}$, the shear strength of the interface layer is $\tau_{s}=0.35 \mathrm{MPa}$, which is consistent with the maximum value in the shear stress distribution curve when the dilatancy angle is $\psi=0$ in Figure 14:

$$
\tau_{s}=\sigma_{n} \tan \varphi_{s}+C_{s},
$$

where $\sigma_{n}$ is the radial stress on the interface layer, $\mathrm{MPa} ; \tau_{s}$ is the shear strength of the interface layer, $\mathrm{MPa} ; \varphi_{s}$ is the internal friction angle of the interface layer, degree; and $C_{s}$ is the cohesion of the interface layer, MPa.

As shown in Figures 16 and 17, when the dilatancy angle is taken into account in the numerical calculation, the maximum radial stress on the interface increases with the dilatancy effect. Due to the dilatancy, no shear failure occurs in the interface layer under the same load condition, which shows that the radial stress generated by the interface dilatancy can improve the shear strength of the interface layer. Figure 17 also shows that, with the increase in the dilatancy angle, the maximum value of the radial stress near the interface layer becomes increasingly larger. When the dilatancy angle increases to a certain value, the influence of the dilatancy angle on the radial stress decreases, which is consistent with the distribution trend of the curve in Figure 15. Figure 17 also shows that the radial stress is the largest near the interface layer and the radial stress decreases rapidly with increasing distance from the interface layer. The range of the radial stress caused by dilatancy is mainly in the interface layer and the rock around the borehole.

\section{Discussion}

Most scholars focus on the influence of the strength characteristics of the grouting material on the anchorage 
mechanism of the anchorage structure. A large number of results show that the strength properties of the grouting material play an important role in the shear stress distribution and axial stress distribution along the rockbolt. However, in this study, the research focus is mainly on the influence of the sand content of the grouting material on the interface dilatancy. Through the research of this paper, many valuable conclusions are obtained. Even so, these studies have many other problems that require discussion and deserve further consideration. It is known that there are many factors that affect the dilatancy angle, and, in special cases, the dilatancy angle also changes with the change in the external conditions, so it is very difficult to accurately obtain the dilatancy angle of the interface layer. Therefore, in the numerical calculation, we can only use different dilatancy angle to simulate the influence of the sand content on the bearing capacity. In future research, the influence of the sand content in the grouting material on the dilatancy angle of the interface should be carried out, and the relationship between the sand content and the dilatancy angle should be established to obtain the quantitative expression of the sand content on the improvement of the interface shear strength. In actual engineering design, on the premise of ensuring the strength of the grouting material and other requirements and according to the research conclusions of this paper, the sand content can be appropriately increased to improve the bearing capacity of the anchorage system. However, this needs to be verified by field tests.

\section{Conclusions}

In this paper, according to the phenomenon of radial splitting of the samples found in the laboratory model test, the mechanism of the interface dilatancy of cement mortar rockbolt is studied. The primary conclusions are summarized as follows:

(1) The sand content of the grouting material has a substantial influence on the ultimate pull-out force of the anchorage system. Under the same conditions, the ultimate pull-out force of the sample increases sharply with increasing sand content in the grouting material.

(2) In the grouting material, the higher the sand content is, the more obvious the dilatancy of the interface will be. The larger the radial stress caused by the interface dilatancy is, the higher the interface shear strength is, and the larger the bearing capacity of the anchorage system is.

(3) Under the same load conditions, as the dilatancy angle of the interface layer increases, the maximum shear stress of the interface layer also increases. Due to dilatancy, radial stress is generated near the interface layer. With the increase in the dilatancy angle, the radial stress increases. Far away from the interface layer, the radial stress decreases rapidly, and the influence of the radial stress is mainly in the interface layer and the rock nearby.
(4) Due to the existence of the radial stress caused by dilatancy, the mechanical properties of the interface layer and the bearing capacity of the anchorage system have been substantially improved. Due to the existence of the interface layer, the interface becomes the weak link of the whole anchorage system. The failure of the anchorage system starts from the position of the interface, and, with increasing stress, relative slip occurs at the interface. If the interface layer can produce dilatancy, the bearing capacity of the anchorage system will be substantially improved.

\section{Data Availability}

The data used to support the findings of this study are included within the article.

\section{Conflicts of Interest}

The authors declare that there are no conflicts of interest regarding the publication of this paper.

\section{Acknowledgments}

This study was supported by the National Natural Science Foundation of China (51804182).

\section{References}

[1] B. Benmokrane, A. Chennouf, and H. S. Mitri, "Laboratory evaluation of cement-based grouts and grouted rock anchors," International Journal of Rock Mechanics and Mining Sciences \& Geomechanics Abstracts, vol. 32, no. 7, pp. 633-642, 1995.

[2] A. R. Akisanya and A. Ivanović, "Debonding along the fixed anchor length of a ground anchorage," Engineering Structures, vol. 74, pp. 23-31, 2014.

[3] A. Ivanović and R. D. Neilson, "Modelling of debonding along the fixed anchor length," International Journal of Rock Mechanics and Mining Sciences, vol. 46, no. 4, pp. 699-707, 2009.

[4] Y.-J. Wang, Z.-M. Wu, J.-J. Zheng, and X.-M. Zhou, "Threedimensional analytical model for the pull-out response of anchor-mortar-concrete anchorage system based on interfacial bond failure," Engineering Structures, vol. 180, pp. 234-248, 2019.

[5] C. Cao, T. Ren, Y. Zhang, L. Zhang, and F. Wang, "Experimental investigation of the effect of grout with additive in improving ground support," International Journal of Rock Mechanics and Mining Sciences, vol. 85, pp. 52-59, 2016.

[6] A. Teymen and A. Kilıç, "Effect of grout strength on the stress distribution (tensile) of fully-grouted rockbolts," Tunnelling and Underground Space Technology, vol. 77, pp. 280-287, 2018.

[7] A. J. Hyett, W. F. Bawden, and R. D. Reichert, "The effect of rock mass confinement on the bond strength of fully grouted cable bolts," International Journal of Rock Mechanics and Mining Sciences \& Geomechanics Abstracts, vol. 29, no. 5, pp. 503-524, 1992.

[8] A. J. Hyett, W. F. Bawden, G. R. Macsporran, and M. Moosavi, "A constitutive law for bond failure of fully-grouted cable bolts using a modified Hoek cell," International Journal of Rock Mechanics and Mining Sciences \& Geomechanics Abstracts, vol. 32, no. 1, pp. 11-36, 1995. 
[9] W. Lu, D. Zhao, X.-F. Mao, and Y. Ai, "Experimental study on bond-slip behavior of bamboo bolt-modified slurry interface under pull-out load," Advances in Civil Engineering, vol. 2018, pp. 1-23, Article ID 6960285, 2018.

[10] F. F. Ren, Z. J. Yang, J. F. Chen, and W. W. Chen, "An analytical analysis of the full-range behaviour of grouted rockbolts based on a tri-linear bond-slip model," Construction and Building Materials, vol. 24, no. 3, pp. 361-370, 2010.

[11] S. Ma, J. Nemcik, and N. Aziz, "An analytical model of fully grouted rock bolts subjected to tensile load," Construction and Building Materials, vol. 49, pp. 519-526, 2013.

[12] S. Ma, J. Nemcik, N. Aziz, and Z. Zhang, "Analytical model for rock bolts reaching free end slip," Construction and Building Materials, vol. 57, pp. 30-37, 2014.

[13] S. Yazici and P. K. Kaiser, "Bond strength of grouted cable bolts," International Journal of Rock Mechanics and Mining Sciences \& Geomechanics Abstracts, vol. 29, no. 3, pp. 279292, 1992.

[14] M. Moosavi, A. Jafari, and A. Khosravi, "Bond of cement grouted reinforcing bars under constant radial pressure," Cement and Concrete Composites, vol. 27, no. 1, pp. 103-109, 2005.

[15] L. B. Martín, M. Tijani, and F. H. Hassen, “A new analytical solution to the mechanical behaviour of fully grouted rockbolt subjected to pull-out tests," Construction and Building Materials, vol. 25, no. 2, pp. 749-755, 2011.

[16] L. B. Martín, M. Tijani, F. H. Hassen, and A. Noiret, "Assessment of the bolt-grout interface behaviour of fully grouted rockbolts from laboratory experiments under axial loads," International Journal of Rock Mechanics and Mining Sciences, vol. 63, pp. 50-61, 2013.

[17] I. Thenevin, L. Blanco-Martín, F. Hadj-Hassen, J. Schleifer, Z. Lubosik, and A. Wrana, "Laboratory pull-out tests on fully grouted rock bolts and cable bolts: results and lessons learned," Journal of Rock Mechanics and Geotechnical Engineering, vol. 9, no. 5, pp. 843-855, 2017.

[18] Ministry of Housing and Urban-Rural Development of the People's Republic of China, JGJ/T70-2009: Standard for Test Method of Performance on Building Mortar, China Architecture and Building Press, Beijing, China, 2009.

[19] K. Zhao, X. Yu, S. Zhu, Y. Zhou, Q. Wang, and J. Wang, "Acoustic emission investigation of cemented paste backfill prepared with tantalum-niobium tailings," Construction and Building Materials, vol. 237, p. 117523, 2020.

[20] K. Zhao, X. Yu, S. Zhu et al., "Acoustic emission fractal characteristics and mechanical damage mechanism of cemented paste backfill prepared with tantalum niobium mine tailings," Construction and Building Materials, vol. 258, Article ID 119720, 2020.

[21] J. C. Jaeger, Elasticity, Fracture and Flow: With Engineering and Geological Applications, pp. 157-158, Wiley Press, New York, NY, USA, 1956.

[22] I. W. Jonston, T. S. K. Lam, and A. F. Williams, "Constant normal stiffness direct shear testing for socketed pile design in weak rock," Geotechnique, vol. 37, no. 1, pp. 83-89, 1987.

[23] M. A. Hossain and J.-H. Yin, "Influence of grouting pressure on the behavior of an unsaturated soil-cement interface," Journal of Geotechnical and Geoenvironmental Engineering, vol. 138, no. 2, pp. 193-202, 2012.

[24] L. J. Su, Y. L. Li, and J. H. Yin, "Numerical study of the influence of soil dilation angle and grouting pressure on the pull-out strength of the soil nail," Journal of Xi'an University of Architecture \& Technology (Natural Science Edition), vol. 4, 2011.
[25] W. H. Zhou and J. H. Yin, "Finite element modeling soil nail pullout behavior and effects of overburden pressure and dilation," Rock and Soil Mechanics, vol. 32, no. s1, pp. 691-696, 2011. 